\title{
Alteridad, lenguaje y ontología en la antropología perspectivista de Eduardo Viveiros de Castro: reflexiones extemporáneas ${ }^{1}$
}

\author{
Alterity, Language, and Ontology in Eduardo Viveiros de \\ Castro's Perspectival Anthropology: Untimely Reflections ${ }^{2}$
}

Fecha de recepción: 12/12/2020

Fecha de aceptación: 23/03/2021

Fecha de publicación: 18/08/2021

https://doi.org/10.48102/if.2021.v1.n2.161

\author{
Aäron Moszowski Van Loon* \\ moszowski75@yahoo.com.mx \\ ORCID: https://orcid.org/0000-0002-9338-3690 \\ Doctor en Filosofía de la Ciencia \\ Escuela Nacional de Antropología e Historia \\ México
}

\begin{abstract}
1 Expreso mi gratitud a Ferdinando Alfonso Armenta, Alma Delia Bermúdez, Víctor Manuel Márquez y Camilo Sempio por sus comentarios críticos a las versiones anteriores de este trabajo. Asimismo, agradezco a Manola Sepúlveda y a los alumnos que durante el periodo 2017-2019 formaron parte del proyecto de investigación formativa "Epistemología y etnografía", que coordino en la Escuela Nacional de Antropología e Historia (ENAH). Por último, extiendo mi agradecimiento a los dos dictaminadores anónimos que evaluaron el artículo. Respecto a los autores citados en el trabajo, para evitar reiteraciones innecesarias, cabe aclarar de antemano que las cursivas provienen de los textos originales, pero que todas las traducciones de las citas en francés e inglés son mías.

2 En "Perspectival anthropology and the method of controlled equivocation", Eduardo Viveiros de Castro (2004) distingue entre la teoría perspectivista amerindia (Amerindian perspectivist theory) y la reconceptualización radical de la antropología heredada con base en ésta, a la que se refiere con el nombre de perspectival anthropology, un matiz que desafortunadamente se pierde al traducirlo al español.

* Maestro y doctor en Filosofía de la Ciencia por la Universidad Nacional Autónoma de México y licenciado en Antropología Social por la Escuela Nacional de Antropología e Historia. Sus investigaciones versan sobre la teoría antropológica contemporánea, la historiografía de la antropología en México y la etnografía y etnohistoria del sur de Durango.
\end{abstract}




\section{Resumen}

En este artículo adopto una mirada más serena y analítica para reexaminar algunos aspectos cruciales de la antropología perspectivista de Eduardo Viveiros de Castro, que durante su reciente apogeo ha sido discutida en términos demasiado polarizados. Al rastrear el uso de "ontología" en el contexto de este controvertido proyecto, evalúo tanto su dimensión metodológica como su dimensión ontológica. Esto no sólo me obliga a enfrentar los problemas de la alteridad y el lenguaje, sino también me lleva a explorar sus vínculos con los llamados "giros ontológicos" en la antropología y en la filosofía contemporáneas. Paralelamente, esbozo algunas pistas prometedoras para guiar la antropología más allá de las dificultades encontradas: el pluralismo epistemológico de Paul Feyerabend y las reflexiones inconclusas de Michel Foucault sobre la práctica de la parrēsia en la antigua Grecia. De esta forma, espero iniciar un diálogo inter y transdisciplinario para tender puentes entre los seguidores y los detractores del proyecto, articulado alrededor del llamamiento esencialmente político de "tomar en serio" el pensamiento nativo.

\section{Palabras clave}

Perspectivismo, giro ontológico, teoría antropológica contemporánea, Paul Feyerabend, Michel Foucault.

\section{Abstract}

In this article, I adopt a more serene and analytical stance in order to reconsider some crucial aspects of Eduardo Viveiros de Castro's perspectival anthropology, which during its recent heyday was discussed in overly polarized terms. By tracking the use of "ontology" in the context of this controversial project, I assess both its methodological and ontological dimensions. This not only compels me to confront the problems of alterity and language but also leads me to explore its links with the so-called "ontological turns" in contemporary anthropology and philosophy. In addition, I outline some promising ways to guide anthropology beyond the encountered difficulties: the epistemological pluralism of Paul Feyerabend and Michel Foucault's unfinished reflections on the practice of parrēsia in ancient Greece. In this way, I hope to start an inter- and transdisciplinary dialogue in order to build bridges between the followers and detractors of the project, articulated around the essentially political call to "take seriously" native thought. 


\section{Keywords}

Perspectivism, ontological turn, contemporary anthropological theory, Paul Feyerabend, Michel Foucault.

\section{Introducción}

Este artículo se enfoca en el etnólogo brasileño Eduardo Viveiros de Castro (EVC, de aquí en adelante) y su proyecto antropológico, íntimamente vinculado con la teoría amerindia del perspectivismo, que, según algunos, "se ha convertido en el paradigma dominante (algunos incluso podrían decir ortodoxia) dentro del que trabaja la mayoría de los antropólogos brasileños y europeos, así como un número cada vez mayor de norteamericanos interesados en la región" (Course, 2010, p. 249). Aun cuando no todos estarían de acuerdo con el autor de la cita anterior, difiero de aquellos que sostienen que se trata de un debate que hoy en día está superado y cuya continuación sólo generaría más polémica innecesaria. Teniendo presente que este proyecto se difundió aceleradamente por los departamentos de antropología en las primeras décadas del siglo XXI y fue discutido en términos extremadamente polarizados durante su reciente apogeo, considero que ha llegado el momento de reexaminarlo de cerca con una mirada más serena y analítica para tender puentes entre sus seguidores y sus detractores. ${ }^{3}$

A un nivel más general, espero mostrar implícitamente que la imagen caricaturesca de la construcción teórica en la antropología como una sucesión de paradigmas kuhnianos con fronteras bien delimitadas podría resultar perjudicial, porque no sólo desalienta el diálogo inter y extraparadigmático, sino también inter y transdisciplinario. Sin olvidar que la noción de paradigma fue introducida posteriormente, resulta muy sugerente voltear la mirada a Otto Neurath, el integrante más heterodoxo del Círculo de Viena, quien comparó las ciencias con navíos incapaces de salirse del mar. Con ello, trató de aclarar que están en construcción permanente y no

3 Esto también aplica para el debate sobre la constelación más amplia de giros ontológicos en la antropología y la filosofía contemporáneas, que abordo en el penúltimo apartado. Muestra extrema de dicha polarización es la crítica hiperbólica de Peter Wolfendale a ciertas vertientes de la filosofía orientada a los objetos (OOP, por sus siglas en inglés). En Object-Oriented Philosophy: The Noumenon's New Clothes, se imagina la escena distópica de un coloquio en 2023 en donde la mesa estelar está integrada exclusivamente por ponentes no humanos. Con su pluma mordaz, apunta que "el debate público subsiguiente converge por unanimidad en que la contribución de un pequeño frasco de mermelada a medio comer [fue] la parte más memorable del evento" (Wolfendale, 2014, p. 392). 
pueden volver a edificarse desde cero sobre fundamentos completamente nuevos e infalibles:

Imagínense unos marineros que, lejos en el mar, transforman la forma de su navío rústico de una más circular a una más parecida a un pez. Aparte de las vigas de la estructura antigua, utilizan algunas vigas a la deriva para modificar el esqueleto y el casco de su navío. Pero no pueden poner el barco en una dársena para empezar desde cero. Durante su labor permanecen en la estructura antigua y lidian con ventarrones y olas estruendosas. Al transformar el barco, se cuidan de que no haya filtraciones peligrosas. Paso a paso, un nuevo barco surge del antiguo. En medio del proceso de construcción, los marineros tal vez ya están ingeniando una nueva estructura. No siempre estarán de acuerdo los unos con los otros. El proceso seguirá su curso de una manera que ni siquiera en este momento se puede prever. Eso es nuestro destino. (O. Neurath, 1944, p. 47)

Desde esta perspectiva, resulta riesgoso cerrar un debate de forma prematura, ya que esto no sólo impide refinar los argumentos en juego, sino también debilita los debates futuros, que se nutren inevitablemente de los anteriores. De allí, pues, la doble relevancia de estas reflexiones extemporáneas sobre EVC.

Más en concreto, me enfoco en los escritos más programáticos de su etapa intermedia ${ }^{4}$ para evaluar tanto la dimensión metodológica como la dimensión ontológica de su proyecto, articulado alrededor del llamamiento esencialmente político de "tomar en serio" el pensamiento nativo. Con estos dos objetivos en mente, presento cuatro apartados: en el primero reúno un conjunto de seis viñetas en donde examino su dimensión metodológica, lo cual me obliga a enfrentar el problema de la alteridad; en el segundo

4 Sin pretensión de establecer una periodización estricta, se resalta el carácter esencialmente etnográfico de sus primeros escritos (véase, por ejemplo, Viveiros de Castro, 1986/ 1992), el carácter programático e intencionalmente polémico de su etapa intermedia (véase, por ejemplo, Viveiros de Castro, 2009/2010a) y el carácter más revisionista de sus publicaciones de los últimos años (véase, por ejemplo, Viveiros de Castro, 2016). Aunque este artículo se nutre principalmente de los escritos de la segunda etapa, incluyo algunas notas al pie de página para contrapuntear lo expuesto en el cuerpo principal del texto y mostrar que el pensamiento de EVC dista de ser monolítico y ha ido evolucionando. 
me centro en el pluralismo epistemológico de Paul Feyerabend para indicar un camino más allá de las dificultades encontradas; en el tercero reúno otro conjunto de seis viñetas en donde abordo la dimensión ontológica del proyecto de EVC, lo cual no sólo me lleva a encarar el problema del lenguaje, sino también a explorar sus vínculos con los llamados "giros ontológicos" en la antropología y la filosofía contemporáneas; y en el cuarto cierro mi pesquisa y dirijo la mirada al chamán yanomami Davi Kopenawa, cuyas palabras parecen indicar que el lugar adonde llegó Michel Foucault en sus reflexiones inconclusas sobre la práctica de la parrēsia en la antigua Grecia y el que se vislumbra en el horizonte desde la antropología perspectivista de EVC no son tan distintos.

Considerando que la originalidad de este artículo reside en parte en el diálogo crítico entre EVC, Feyerabend y Foucault, adelanto la pregunta alrededor de la que se articula este último apartado y en la que se perfilan los elementos que hay que desmenuzar paso por paso a lo largo de los otros apartados antes de esbozar una respuesta posible. ¿Quién se encuentra en una posición más favorable para atravesar las barras de la jaula del lenguaje: el antropólogo perspectivista, que hace recaer el peso en la alteridad de aquellos cuyo pensamiento es "tomado en serio", o el parrēsiastēs, que por sus cualidades morales singulares puede hacer coincidir performativamente lo que piensa, lo que dice, lo que hace y "lo que hay"?

\section{La seriedad como metodología y el problema de la alteridad: seis viñetas}

En "And", un discurso de sobremesa pronunciado en 2003 y considerado por algunos un "manifiesto explícito" (Henare et al., 2007, p. 8), EVC opone dos tipos de antropología: una contribuye a domesticar a los llamados "nativos" al recurrir a conceptos extrínsecos a su pensamiento para explicar, interpretar, contextualizar y racionalizarlo; la otra rehúye todo lo anterior y se propone "tomar en serio" (levar a sério, en portugués; to take seriously, en inglés) este pensamiento, apostando por la "autodeterminación ontológica de los pueblos del mundo" como un complemento indispensable de su autodeterminación política. Respecto a la segunda, que asume como la suya, expresa en dicha conferencia lo siguiente: 
el verdadero objeto de la antropología no son las epistemologías, sino las ontologías. [...] Esto funciona como un antídoto ante el truco desrealizador [derealizing trick] utilizado a menudo en contra del pensamiento nativo, que lo convierte en una especie de fantasía duradera al reducirlo a las dimensiones de una forma de conocimiento o representación, es decir, una "epistemología" o una "cosmovisión". (Viveiros de Castro, 2003/2015a, pp. 53-54)

He aquí, en pocas palabras, los ejes rectores del proyecto antropológico de EVC, que pone en primer plano la apuesta política subyacente.

Detecto al menos dos dificultades. La primera concierne a la viabilidad metodológica de una antropología que aplica a la letra el "tomar en serio", que EVC defiende como una respuesta directa al "derecho [de los pueblos] a decidir lo que ellos entienden por realidad" (Viveiros de Castro, 2014, pp. 238-239). Como aclara Matei Candea, esto involucra "una suspensión autoimpuesta [de] lo que ocurre en 'el curso normal de la interacción social', [donde se] disuelve la posibilidad del mundo del otro al convertirlo en la realidad de nuestro propio mundo o en una mera fantasía" (Candea, 2011, p. 147). De hecho, agrega, hay que "rehuir tanto el asentimiento como la crítica para posibilitar que las propias personas hagan explícitas las condiciones bajo las cuales hay que aprehender lo que dicen" (Candea, 2011, p. 147).

Más allá de los problemas prácticos que eso conlleva -¿qué hacer cuando alguien se niega a especificar dichas condiciones o cómo evitar un regreso al infinito en donde uno está obligado a especificar cómo aprehender lo que dijo, lo que dijo sobre lo que dijo, etcétera?-, cabe preguntarse por las implicaciones de suspender el "curso normal de la interacción social". En efecto, se trata de algo al que el propio EVC remite explícitamente en "Zeno and the art of anthropology: Of lies, beliefs, paradoxes, and other truths", en donde polemiza con Richard Rorty y Gilles Deleuze: mientras que se distancia del primero, cuyo pragmatismo desemboca en un relativismo que asume la coexistencia de "muchas visiones" que no podemos tomar en serio, reivindica al segundo, que invita a mantener como posibilidades todo aquello que suele actualizarse en "el curso normal de la interacción social", lo cual implica no transformarlo en una mera creencia ni tomarlo literalmente (Viveiros de Castro, 2011, p. 130-137). 
En Los espíritus y sus mundos: Locura y subjetividad en el México moderno y contemporáneo, Zenia Yébenes reconceptualiza lo social en el contexto de la experiencia moderna del lenguaje a partir de la noción de "exceso", que introduce para poner de relieve que no se puede excluir la posibilidad de que el significado inicial de una secuencia de acciones o palabras se transforme radicalmente cuando se agrega otro elemento a ésta (Yébenes, 2014, p. 41). Retomando un ejemplo de Molly Anne Rothenberg, aclara el meollo del asunto: "Cuando leemos 'Sonreía al acariciar suavemente la piel aterciopelada de su amante', esta escena de amor inicial se altera retrospectivamente (deja de significar lo que significaba) al leer después la siguiente frase: 'con el filo agudo de un cuchillo"' (Yébenes, 2014, p. 41). De allí el doble imperativo contradictorio al que se enfrenta el sujeto moderno: la apertura de la significación hace necesario seguir participando en lo social para intentar asentar el significado; empero, al mismo tiempo es necesario disimular el exceso y asentar provisionalmente el significado para interactuar con un mínimo de predictibilidad. En las palabras de otro antropólogo, "Disimulamos. Actuamos y tenemos que actuar [...] como si el piso a nuestro alrededor estuviera firme. [...] Intenten imaginarse qué ocurriría si en nuestra práctica cotidiana no conspiráramos para olvidar lo que Saussure llamó 'la arbitrariedad del signo"' (Taussig, 1993, pp. xvii-xviii).

Desde esta perspectiva, la incitación a "tomar en serio" el pensamiento nativo es potencialmente problemática. En efecto, cabe preguntarse por las diferencias entre, por un lado, alguien que al toparse con los llamados "nativos" rehúye voluntariamente la clausura de la significación y, por el otro, los esquizofrénicos con los que Yébenes interactuó en su investigación y de los que resalta sobre todo su "observación hipercrítica [...] de lo que habitualmente en la existencia social tomamos por garantizado. Por ejemplo, me [hizo] ver D., el absurdo del ritual social de saludar diciendo "hola"' (Yébenes, 2014, p. 20). Por otra parte, que esta suspensión situacional del curso normal de la interacción social podría ser desconcertante para aquéllos hacia los que se dirige es otro elemento para tomar en cuenta: rehuir tanto el asentamiento como la crítica podría resultar disruptivo para alguien que espera entablar irreflexivamente un diálogo con otra persona. 
De hecho, a diferencia de la hiperreflexividad esquizofrénica, la seriedad de EVC es selectiva. Como aclara en "Zeno and the art of anthropology: Of lies, beliefs, paradoxes, and other truths", "al tiempo que nos esforzamos por tomar en serio cosas que están lejos o fuera de nosotros, casi todas las cosas que no hay que tomar en serio están cerca o dentro de nosotros" (Viveiros de Castro, 2011, p. 133). Refiriéndose directamente al texto anterior, Candea aclara el punto: "A diferencia de los amazónicos, Rorty y Deleuze no son tomados en serio [por EVC]. Al contrario, el mundo posible de Rorty es verificado y rechazado, mientras que el mundo posible de Deleuze es verificado y brinda una definición de la antropología" (Candea, 2011, p. 148). En otras palabras, el "tomar en serio" conlleva el tratamiento diferencial del pensamiento de aquéllos cerca o dentro de nosotros - en este caso, dos filósofos occidentales- y el de aquéllos lejos o fuera de nosotros.

Pero ¿dónde está el límite? La respuesta de EVC es sencilla: "ser antropólogo es dividir la raza humana en aquellos cuyas creencias uno puede cuestionar legítimamente y los otros" (Viveiros de Castro, 2011, p. 136). Aunque de inmediato pone en tela de juicio sus propias palabras - "cada persona es un pueblo en sí [...] No hay mucho margen para un cuestionamiento legítimo de creencias que no son las de uno mismo" (Viveiros de Castro, 2011, p. 136)-, se trasluce algo espinoso: la dicotomía entre "nosotros" y "ellos". A mi parecer, se trata del talón de Aquiles de su proyecto, cuyos adherentes parecen estar obligados a pronunciarse de forma apriorística sobre la alteridad de quienes tienen enfrente para seguir o suspender el curso normal de la interacción social. Antes de elaborar este punto, recurro a un ejemplo etnográfico para resaltar algunas de las dificultades prácticas que acarrea el "tomar en serio" en sentido estricto.

En "Reírse ante la guerra: Las bromas como actuación política entre los muina, Amazonia colombiana", Marco Tobón argumenta que las bromas utilizadas por los indígenas de la Amazonia colombiana en las juntas convocadas por la guerrilla o el ejército colombiano no sólo son la manifestación viva de su cultura, sino también herramientas políticas orientadas a mantener su posición autónoma al margen del conflicto armado. Por ejemplo, durante una reunión en 2002 , 
varios guerrilleros llamaron [al] gobernador del resguardo [...] fuera de la maloca. Los asistentes se sintieron advertidos [...] De repente, otro líder muinane [...] les dijo en modo jocoso y en voz alta para que todas las personas escucharan: "Camaradas, pueden matar a este señor, además tiene como 20 mujeres y yo me puedo encargar de ellas". Todos los asistentes, incluidos los guerrilleros, se echaron a reír. (Tobón, 2016, p. 197)

Respecto a la incitación a "tomar en serio" el pensamiento nativo y la disposición correspondiente de suspender el curso normal de la interacción social, el fragmento anterior pone en la mesa varias cuestiones espinosas. En primer lugar, revela que el "tomar en serio" no necesariamente favorece a aquéllos a quienes se dirige. En este caso particular, y recordando que "tomar en serio" y "tomar literalmente" no son sinónimos, la situación explosiva se destensó precisamente porque los guerrilleros no decidieron tomarse el tiempo para "tomar en serio" las palabras del líder muinane y posibilitar que éste especificara las condiciones bajo las cuales habría que aprehenderlas. Todo lo contrario, se rieron de inmediato, siguiendo irreflexivamente el curso normal de la interacción social. En segundo lugar, el episodio también obliga a examinar de cerca las implicaciones de "tomar en serio" el pensamiento de aquéllos "lejos o fuera de nosotros" y no el de aquéllos "cerca o dentro de nosotros". Dado que la cercanía y la lejanía son relativas al contexto de interacción social, hipotéticamente son posibles al menos tres escenarios: si los guerrilleros resultan "cercanos" y los muinane "lejanos", ¿qué entrañaría criticar la misoginia difícilmente negable de los guerrilleros, que se rieron, mas no la misoginia a primera vista sólo aparente pero no imposible del líder muinane, que contó la broma?; o al revés, si los guerrilleros resultan "lejanos" y los muinane "cercanos", ¿qué implicaría cuestionar al líder muinane mas no a los guerrilleros?; y por último, tal vez más delicado aún, si tanto los guerrilleros como los muinane resultan "lejanos", ¿qué significaría abstenerse de entablar un diálogo crítico con aquéllos "lejos o fuera de nosotros" ? ${ }^{5}$ En tercer lugar, considerando el carácter

5 A modo de contraste, resulta esclarecedor adelantar algunos apuntes sobre Paul Feyerabend, al que dirijo la mirada en el siguiente apartado. Sin olvidar que su concepto de "tradición" emana de los debates historicistas en la filosofía de la ciencia, su llamamiento político por la irrestricta igualdad de derechos y oportunidades para todas las tradiciones tanto científicas como no científicas -he aquí el núcleo de su relativismo político, que complementa su plu- 
político -y, por lo tanto, práctico- del llamamiento de "tomar en serio" el pensamiento nativo, el encuentro reconstruido por Tobón sugiere que es indispensable preguntarse por las posibles discordancias entre lo que el antropólogo hace en el campo y escribe en el gabinete, donde es más factible suspender retrospectivamente el curso normal de la interacción social.

Volviendo explícitamente al problema de la alteridad, cabe esbozar a vuelapluma las coordenadas del universo etnográfico del propio EVC. Con base en su trabajo de campo entre los araweté de la Amazonia brasileña, cuyo pensamiento decidió "tomar en serio", formula la teoría amerindia del perspectivismo, según la cual "todos los seres ven [...] el mundo de la misma manera: lo que cambia es el mundo que ven" (Viveiros de Castro, 2009/2010a, p. 53). Paralelamente, EVC introduce la noción de multinaturalismo para resaltar su dimensión ontológica: "en tanto [las concepciones multiculturalistas modernas] se apoyan en la implicación mutua entre la unicidad de la naturaleza y la multiplicidad de las culturas [...], la concepción amerindia supondría [...] una unidad del espíritu y una diversidad de los cuerpos" (Viveiros de Castro, 2009/2010a, p. 34).

¿Qué idea de alteridad se trasluce detrás de todo ello? El viaje etnográfico que inició con una suposición de lejanía y exterioridad - si no, no habría tomado en serio el pensamiento de los araweté- desemboca en una idea mucho más radical de alteridad, basada en una generalización que opone dos ontologías inconmensurables: el multinaturalismo amerindio, que EVC describe como una "cosmología contra el Estado" (Viveiros de Castro, 2010b, p. 25), y el mononaturalismo occidental, que es indisociable de las "dicotomías infernales -unidad-multiplicidad, universalismo-relativismo, representación-realidad y naturaleza-cultura (por mencionar sólo algunas) - que constituyen las barras de nuestra jaula metafísica" (Viveiros de Castro, 2011, p. 129). ${ }^{6}$

ralismo epistemológico- sólo excluye la crítica exclusivamente externa (Suárez, 2008, pp. 119-153). Según Feyerabend, aun cuando la crítica más poderosa es la interna, no se puede excluir la posibilidad de que la combinación de la crítica interna y externa es provechosa para la tradición criticada, ya que, si logra resistir, sale fortalecida.

6 No hay duda de que esta oposición atraviesa la obra de EVC, pero él mismo la matiza en algunos de sus trabajos. Por ejemplo, en "Cosmological perspectivism in Amazonia and elsewhere (Four lectures given in the Department of Social Anthropology, University

Moszowski, A. (2021). Alteridad, lenguaje y ontología en la antropología perspectivista de Eduardo Viveiros de Castro: reflexiones extemporáneas. Iberoforum. Revista de Ciencias Sociales, Nueva Época, 1(2), 1-33, Artículos, e000161. https://doi.org/10.48102/if.2021.v1.n2.161 Licencia Pública Internacional - CC BY-NC-ND 4.0 
Con ello, EVC se coloca en una posición diametralmente opuesta a los doce colaboradores de Beyond Alterity: Destabilizing the Indigenous Other in Mexico (López y Acevedo-Rodrigo, 2018), quienes cuestionan la alteridad atribuida a los indígenas - entre otros, por aquellos que, siguiendo a Clastres, contraponen las "sociedades con Estado" a las "sociedades contra el Estado"- y proponen aproximarse a ellos desde una orientación más allá de la alteridad, para lo que es imprescindible tener en cuenta su imbricación con el Estado-nación. Según ellos, no se trata de desmentir que haya diferencias, sino de poner de relieve que alguien que se centra exclusivamente en éstas corre el peligro de eclipsar las similitudes y naturalizar a los indígenas como "otros".7

De hecho, no sólo existe la sospecha de que la supuesta alteridad de aquellos cuyo pensamiento es "tomado en serio" se confirma a modo de una profecía autocumplida, sino también de que se exacerba. Aunque los antropólogos afines a EVC lo niegan explícitamente, muchos de sus detractores temen que contribuyan a "ontologizar" las diferencias e instaurar lo que algunos describen como una especie de "apartheid ontológico" (Laidlaw, 2012, s.p.). Sea como fuere, entre los críticos y los simpatizantes de EVC existe un amplio consenso de que la noción de alteridad en la que se sustenta su proyecto y al que suele añadirse el adjetivo "radical" resulta problemática porque es difícil de disociar de la idea de conllevar, tal vez inadvertidamente, la esencialización y la exotización de aquellos cuyo pensamiento es "tomado en serio" (véase, por ejemplo, González, 2015, pp. 5255; dos Santos y Tola, 2016, pp. 80-81; González-Abrisketa y Carro-Ripalda, 2016, pp. 116-117; Reygadas, 2019, pp. 80-85). ${ }^{8}$

of Cambridge, February-March 1998", apunta que no se trata del resultado de una comparación, sino de una posible generalización entre otras que decidió elaborar por razones pragmáticas y políticas (Viveiros de Castro, 2015b, pp. 211-212). En dos publicaciones más recientes, resalta "el marcado contraste -deliberadamente provocador y por eso excesivamente simplista- entre multiculturalismo y multinaturalismo" (Holbraad y Viveiros de Castro, 2016, p. 3) y aclara que se trata de "un exotismo estratégico (o, si se prefiere, una alterización [othering] metodológica" (Viveiros de Castro, 2016, p. 257).

7 El propio EVC se adelantó a esta crítica señalando que aquellos que enfatizan las semejanzas entre los indígenas y los no indígenas son más susceptibles de ser portadores involuntarios de supuestos esencialistas (Viveiros de Castro, 2015b, p. 212). Sin duda, se trata de una contracrítica acertada, porque los esencialismos monistas son más fáciles de pasar por alto, pero de allí no se sigue que no haya esencialismos dualistas.

8 Por ejemplo, Luis Reygadas enmarca su revisión del proyecto de EVC en su crítica mucho más amplia de los dualismos críticos, que delimita como aquellas "perspectiva[s] con

Moszowski, A. (2021). Alteridad, lenguaje y ontología en la antropología perspectivista de Eduardo Viveiros de Castro: reflexiones extemporáneas. Iberoforum. Revista de Ciencias Sociales, Nueva Época, 1(2), 1-33, Artículos, e000161. https://doi.org/10.48102/if.2021.v1.n2.161 Licencia Pública Internacional - CC BY-NC-ND 4.0 


\section{Reflexiones intermedias: ¿más allá de la alteridad?}

Tal vez Paul Feyerabend podría ayudar a indicar un camino más allá de las dificultades encontradas en las viñetas anteriores, que pusieron en tela de juicio la noción de alteridad que subyace al proyecto antropológico de EVC. En Tratado contra el método: Esquema de una teoría anarquista del conocimiento, el filósofo de la ciencia reconstruye algunos episodios en la historia de las ciencias para mostrar que "todas las metodologías, incluso las más obvias, tienen sus límites" (Feyerabend, 1975/1986, p. 17), tesis que respalda argumentativamente con base en la reducción al absurdo en donde el a menudo malentendido principio "todo vale" (anything goes, en inglés) ocupa un lugar central. He aquí, pues, la base de su posición posfundacionalista, que parte del supuesto de que "todo sirve para algo mas no para todo" e incita a reemplazar la búsqueda infructuosa de fundamentos últimos por la búsqueda posible y necesaria de fundamentos provisionales, cuya adopción tiene que justificarse en cada caso particular.

¿Qué se sigue de ello para el "tomar en serio"? Sin duda, Feyerabend celebraría el gesto iconoclasta subyacente a esta maniobra metodológica, pero no aceptaría que se implementara de forma dogmática para aplicarse en bloque al pensamiento de aquéllos "lejos o fuera de nosotros" y no aplicarse en bloque al de aquéllos "cerca o dentro de nosotros". Aparte de las dificultades de establecer la frontera entre lo lejano y lo cercano en términos no esencialistas, al proceder de esta forma, uno no sólo evade la responsabilidad de justificar sus decisiones metodológicas concretas - ¿por qué "tomar en serio" o no esta idea, y no otra, de esta persona, y no otra?-, sino también corre el riesgo de socavar el pluralismo epistemológico del que se nutre la propia ciencia. De hecho, teniendo presente la tesis de la carga teórica de la observación, que destronó la observación como árbitro neutral, Feyerabend sostiene que la mejor manera de fortalecer una teoría es tratar de atacarla por medio de la exploración de la mayor cantidad posible de alternativas, ya que éstas pueden sacar a la luz datos que la refutan, pero que ella misma es incapaz de revelar. Así, no sólo se impide que una

orientaciones transformadoras, que toma[n] partido por los grupos subalternos y las causas emancipadoras, pero que analiza[n] los fenómenos sociales de manera dualista, destacando la oposición radical y la diferencia irreductible, esencial, entre dos mitades del mundo" (Reygadas, 2019, p. 80). Evidentemente, el propio Reygadas, quien defiende que "nunca hay ni alteridad radical ni mismidad o identidad radical" (Reygadas, 2019, p. 83), está sujeto a la contracrítica de EVC señalada en la nota al pie de página anterior.

Moszowski, A. (2021). Alteridad, lenguaje y ontología en la antropología perspectivista de Eduardo Viveiros de Castro: reflexiones extemporáneas. Iberoforum. Revista de Ciencias Sociales, Nueva Época, 1(2), 1-33, Artículos, e000161. https://doi.org/10.48102/if.2021.v1.n2.161 Licencia Pública Internacional - CC BY-NC-ND 4.0 
teoría en particular se erija como un dogma, sino también se propicia el progreso en términos de abundancia.

Respecto a los límites del "tomar en serio", un breve vistazo a un fragmento de la extensa obra de Michael Taussig, uno de los antropólogos más radicales de las décadas de 1970 y 1980, permite ilustrar lo que está en juego. En 1997 publicó The Magic of the State, una etnografía desconcertante elaborada con base en su trabajo de campo en Venezuela y, al igual que la mayoría de sus otros libros, escrita en forma de montaje literario. En este caso, adicionalmente, disuelve las fronteras entre la ficción y la no ficción para tratar de aprehender la naturaleza elusiva del Estado-nación moderno. Para ello, en lugar de tomar las verdades como metáforas de las que se ha olvidado que lo son, tal como propuso Nietzsche, invita a tomar las metáforas como verdades de las que se ha olvidado que lo son: al igual que en los rituales de posesión espiritual, en donde la materialización de los espíritus de los caídos literalmente potencia a los poseídos, las invocaciones mántricas a los héroes nacionales - “iviva Bolívar!”, “iviva San Martín!”- quizás son acontecimientos no metafóricos que permiten dar a luz a "lo que hay".

Aun cuando Feyerabend no tendría ningún problema con alguien que se deja guiar ocasional y estratégicamente por la divisa "Dejemos que los hechos hablen por sí mismos. Y quiero decir efectivamente hablar" (Taussig, 1997, p. 91), tal maniobra se deslizaría por las mallas de la red extendida por EVC: respecto a los funcionarios del Estado que Taussig describe como el European Elsewhere, no queda claro si se trata de "ellos" o "nosotros"; si se tratase de "ellos", no se "tomó en serio" su pensamiento, porque se contravino el sentido nativo; en cambio, si se tratase de "nosotros", en lugar de aceptar o criticar su pensamiento, se lo tomó literalmente, aunque no en su totalidad.

Como quiera que sea, estoy convencido de que el pluralismo epistemológico de Feyerabend constituye una herramienta muy valiosa para fortalecer el proyecto de EVC, porque obliga a recalibrar la relación entre los llamados "nativos" y los antropólogos. Sin duda, es acertada la crítica a la antropología heredada que subyace al llamamiento esencialmente político de "tomar en serio" el pensamiento nativo, porque ésta colocó casi todo el peso del lado de sus propios conceptos y teorías. Empero, el "tomar en serio" en sentido estricto resulta problemático, porque parte de la 
alteridad de los nativos para colocar casi todo el peso de lado de éstos. ${ }^{9}$ En cambio, si este último pusiera entre paréntesis el concepto de alteridad y se propusiera justificar tanto en el campo como en el gabinete sus decisiones metodológicas concretas de "tomar en serio" esta u otra idea, se perfilaría un proyecto más sólido, que podría contribuir sustancialmente al debate contemporáneo sobre la alteridad, que requiere problematizarse en vez de asumirse como un punto de partida inamovible. ${ }^{10}$

Evidentemente, con ello el proyecto antropológico de EVC perdería su condición excepcionalista, ya que no sería posible erigir una barrera infranqueable entre éste y las antropologías anteriores. Aun así, a mi juicio, conllevaría muchas más ventajas que desventajas. Me limito a resaltar dos. Para empezar, esto permitiría tender puentes entre sus seguidores y sus detractores, quienes se centran sobre todo en los efectos perniciosos de la alterización (othering, en inglés), pero de ningún modo rechazan la apuesta política subyacente a su proyecto. Por otra parte, el reacercamiento entre la antropología heredada y la de EVC alentaría sustancialmente el diálogo inter y extraparadigmático, alimentando el pluralismo epistemológico tan necesario para la ciencia.

9 No se trata de invisibilizar la labor del antropólogo, sino de radicalizar la reflexividad antropológica, como subraya Martin Holbraad (2014, pp. 133-134). De hecho, el propio EVC apunta que "nunca se puede enfatizar demasiado [que se trata de] una (re)construcción experimental del antropólogo [que] necesariamente contiene una contradescripción de nuestra propia metafísica" (Viveiros de Castro, 2016, pp. 259-260). Sin embargo, en el contexto de esta reflexividad exacerbada el peso de la justificación recae esencialmente en la alteridad de los nativos y no en las decisiones metodológicas concretas de aquellos que "toman en serio" su pensamiento y elaboran las etnografías correspondientes.

10 Hay antropólogos afines a EVC que han tratado de hacer esto en años recientes. Por ejemplo, en "La contemporaneidad del ritual indígena", Johannes Neurath (2020) rechaza la dicotomía entre la comunidad tradicional ritualista y la sociedad moderna atomizada, argumentando que en los rituales huicholes se encuentra una conciencia de crisis similar a la que subyace al arte moderno y contemporáneo. 


\section{La ontología como mundo y el problema del lenguaje:}

otras seis viñetas

Después de haber ponderado la viabilidad metodológica de una antropología que aplica a la letra el "tomar en serio", llegó el momento de poner en la mesa de discusión la segunda dificultad que diviso: su dimensión ontológica. Examinemos de cerca un pequeño fragmento de un texto de EVC que ya tuvimos en las manos. En Metafísicas caníbales: Líneas de antropología postestructural, escribe que "el perspectivismo supone una epistemología constante y ontologías variables: las mismas representaciones, otros objetos; sentido único, referencias múltiples" (Viveiros de Castro, 2009/2010a, p. 57).

¿En qué radica la dificultad? Al equiparar los términos de epistemología, representación y sentido, por un lado, y los de ontología, objeto y referencia, por el otro, EVC polariza la diferencia entre una epistemología, en tanto teoría del conocimiento, y una ontología, en tanto teoría de "lo que hay", que además parece identificar directamente con "lo que hay". Mas no sólo eso. Paralelamente, polariza la diferencia entre una antropología cuyo objeto son las epistemologías o las "visiones del mundo" (Viveiros de Castro, 2011, p. 133) y otra cuyo objeto son las ontologías o los "mundos de la visión" (Viveiros de Castro, 2011, p. 133) y que, por lo tanto, tendría un anclaje bastante distinto en la realidad que la primera. ${ }^{11}$ Evidentemente, si hubiera yuxtapuesto los términos de teoría (es decir, epistemología, ontología, etcétera), representación y sentido, por un lado, y los de mundo, objeto y referencia, por el otro, su argumento habría sido menos polémico: desde esta perspectiva,

11 En algunos de sus trabajos posteriores matiza su posición. Por ejemplo, en "Ideas of savage reason: Glass Bead in conversation with Martin Holbraad and Eduardo Viveiros de Castro", se distancia de la "comparación de ontologías" y reivindica la "comparación como ontología", que es ontológicamente agnóstica (Holbraad y Viveiros de Castro, 2016, pp. 3-4). Por otra parte, en "Metaphysics as mythophysics: Or, why I have always been an anthropologist", reconstruye su encuentro con la palabra de ontología, que utilizó por primera vez en 1998: "Mi problema era la reducción de la cultura [...] a una forma de conocer, clasificar y organizar el mundo; en otras palabras, a una epistemología. [...] el problema es que concebimos la cultura de los otros en términos de nuestros conceptos de cultura-y-naturaleza [...] Sólo hay una naturaleza, la nuestra, y luego dos culturas, la nuestra y la suya. [...] Tendríamos que tener una cultura y una naturaleza a ambos lados de la valla comparativa y, por lo tanto, también una epistemología y una ontología" (Viveiros de Castro, 2016, p. 271n22). 
el perspectivismo no supondría una epistemología constante y ontologías variables, sino una epistemología constante y mundos variables.

El lector objetará que eso es perfectamente compatible con la forma en la que lo introduje líneas arriba. Éste es precisamente el punto. Aunque la conflación de los términos de "mundo" y "ontología" no es ejecutada consistentemente a lo largo de toda su obra, ${ }^{12}$ la presencia de múltiples otros casos permite hacer dos lecturas distintas: una primera con un alcance ontológico mínimo, en donde se reconstruye una teoría multinaturalista; y otra con un alcance ontológico máximo, en donde estos múltiples mundos son aprehendidos por medio de la implementación de una teoría no representacionalista del lenguaje..$^{13}$

Al respecto, también resulta muy ilustrativo yuxtaponer algunos fragmentos del influyente escrito colectivo "Ontology is just another word for culture: Motion tabled at the 2008 meeting of the group for debates in anthropological

12 Otros dejan mucho menos lugar a dudas. Olatz González-Abrisketa y Susana Carro-Ripalda resaltan "la confusión que en [las antropologías de corte ontológico] opera a veces entre lo óntico (definido como la existencia en sí de las cosas, independientemente del pensamiento humano) y lo ontológico (definido como el o los discursos acerca de la naturaleza del ser [...])" (González-Abrisketa y Carro-Ripalda, 2016, p. 120), pero equiparan los términos de "ontología" y "mundo" en más de una ocasión. Por ejemplo, al presentar el volumen Thinking Through Things: Theorising Artefacts Ethnographically, señalan que las propuestas de los autores apuntan al descubrimiento de "la multiplicidad de ontologías, de mundos o naturalezas, que existen realmente" (González-Abrisketa y Carro-Ripalda, 2016, p. 106).

13 En su revisión del estudio de las ontologías en la antropología, en el que EVC ocupa un lugar central y al que dirijo la mirada en las páginas siguientes, Sergio Armando González resalta al menos dos flancos débiles: por un lado, la idea de alteridad radical (véase supra); y, por el otro, el "literalismo", con el que se refiere al "movimiento anti[r]representacional que el estudio de ontologías parece sugerir" (González, 2015, p. 55). Más en concreto, sostiene que eso "parece implicar tomar nuestras conversaciones con nuestros 'informantes' de forma intrínsecamente literal, sin ninguna alusión metafórica" (González, 2015, p. 56). Dos veces no. Para empezar, como señalé anteriormente, "tomar en serio" y "tomar literalmente" no son sinónimos, ya que, en el caso de EVC, se trata de posibilitar que los propios nativos especifiquen las condiciones bajo las cuales habría que aprehender sus palabras, lo cual no excluye el uso de metáforas, si ellos así lo especifican. Por otra parte, como aclararé posteriormente, el impulso antirrepresentacionalista concierne a la relación entre lo que el antropólogo escribe y aquello sobre el que escribe, que, en el caso de EVC, está anclada en la posibilidad de reivindicar implícitamente un nuevo realismo directo capaz de garantizar un acceso no mediado por el lenguaje a "lo que hay", lo cual sí excluye el uso de metáforas, pero por parte del antropólogo.

Moszowski, A. (2021). Alteridad, lenguaje y ontología en la antropología perspectivista de Eduardo Viveiros de Castro: reflexiones extemporáneas. Iberoforum. Revista de Ciencias Sociales, Nueva Época, 1(2), 1-33, Artículos, e000161. https://doi.org/10.48102/if.2021.v1.n2.161 Licencia Pública Internacional - CC BY-NC-ND 4.0 
theory", en donde aparecen las voces de cinco antropólogos en mayor o menor grado afines a EVC que en 2008 se reunieron en la Universidad de Manchester para debatir la tesis de que "ontología es tan sólo otra palabra para cultura":

- Soumhya Venkatesan, quien moderó el debate, definió las ontologías como "teorías del ser y la realidad", resaltando que "entre los temas que salieron consistentemente en las presentaciones se destaca la cuestión de cómo lidiamos con la semejanza y la diferencia [...] Ambos términos -'ontología' y 'cultura'- se relacionan estrechamente con este asunto" (Venkatesan et al., 2010, pp. 154-155).

- Por su parte, Michael Carrithers adujo que "una ontología [es] un conjunto de proposiciones, que instaura un punto de vista particular sobre la realidad. [No es] la propia realidad" (Venkatesan et al., 2010, p. 160). Enseguida, aceptó la tesis, aclarando que "ontología es tan sólo otra palabra (entre muchas) para cultura” (Venkatesan et al., 2010, p. 167).

- Karen Sykes, en cambio, la rechazó, delimitando la ontología como "una indagación acerca de cómo ser en el mundo" y la cultura como "un proceso creativo por medio del cual los integrantes de una sociedad responden con inventiva las preguntas ontológicas" (Venkatesan et al., 2010, p. 169).

- A su vez, Matei Candea sostuvo que "'cultura [...] puede ser tan adecuada como ontología [...] para captar no tan sólo una pluralidad de visiones del mundo, sino una multiplicidad real de mundos. [...] Ontología es otra palabra para cultura" (Venkatesan et al., 2010, p. 174). - Martin Holbraad, por último, remató apuntando que "rechazar la tesis es rechazar la idea [...] de que las diferencias [...] tienen que ser ipso facto diferencias de cómo las personas representan el mundo. [...] la alteridad depende de la existencia de distintos mundos" (Venkatesan et al., 2010, pp. 182-183).

Retomando el hilo de la nota anterior, pero sin pretensión de agotar el debate, me limito a agregar que tal vez hubiera sido más apropiado haberse preguntado primero si "lo que hay" es tan sólo otro término para "cultura" y luego si "ontología" es tan sólo otro término para "teoría de la cultura". Sin duda, EVC tiene razón al apuntar en la conferencia "And" de 2003 que "necesitamos una nueva teoría de la teoría [...] que nos permita 
pensar la actividad teórica en continuidad radical con la práctica" (Viveiros de Castro, 2003/2015a, p. 51), pero hay que tener presente que problematizar la relación entre las palabras y las cosas -entre la palabra "mundo" y el mundo, por ejemplo- no es lo mismo que problematizar la relación entre las cosas y una teoría de las cosas -entre el mundo y una teoría del mundo, por ejemplo-. Además, no cabe pasar por alto que las epistemologías también son teorías y no sólo palabras.

Ahora bien, al igual que los antropólogos Roy Wagner y Marilyn Strathern, EVC es considerado uno de los abanderados del giro ontológico que Martin Holbraad y Morten Axel Pedersen presentan en The Ontological Turn: An Anthropological Exposition. Para evitar cualquier confusión, cabe aclarar de inmediato que este giro sui generis forma parte de la constelación mucho más amplia de giros ontológicos en la antropología y la filosofía contemporáneas, cuya extensión pone al descubierto el alcance del movimiento en el que EVC se encuentra inmerso.

De hecho, Holbraad y Pedersen enumeran otros cuatro giros ontológicos, con los que comparten "el deseo de hacer las preguntas ontológicas 'prohibidas' que la filosofía moderna nos enseñó durante siglos a no formular [...], incluyendo el intento de minar y deshacerse del concepto humanista de anthropos" (Holbraad y Pedersen, 2017, p. 35), algo que por lo general desemboca en el rechazo de las llamadas "dicotomías modernas" y la adopción de una posición antirrepresentacionalista: (1) el realismo especulativo y la filosofía orientado a los objetos (OOP, por sus siglas en inglés), entre cuyos representantes se resaltan los filósofos Graham Harman y Quentin Meillassoux, el hijo del antropólogo marxista Claude Meillassoux; (2) los estudios sobre la ciencia y la tecnología (STS, por sus siglas en inglés), que encuentran su expresión máxima en la teoría del actor-red (ANT, por sus siglas en inglés) de Bruno Latour; (3) el giro ontológico asociado al rastreo etnográfico de ontologías no modernas, que agrupa a Marisol de la Cadena, Matei Candea, Donna Haraway, Tim Ingold y Eduardo Kohn, entre otros; y (4) el giro ontológico asociado a la construcción de una ontología comparativa subyacente a la llamada "ontología moderna" y otras ontologías, en donde Philippe Descola ocupa un lugar destacado.

Pero ¿cuál es el rasgo distintivo del giro ontológico de Holbraad y Pedersen? He aquí su respuesta: de Castro: reflexiones extemporáneas. Iberoforum. Revista de Ciencias Sociales, Nueva Época, 1(2), 1-33, Artículos, e000161. https://doi.org/10.48102/if.2021.v1.n2.161 Licencia Pública Internacional - CC BY-NC-ND 4.0 
su interés perenne por liberar el pensamiento de cualquier fundacionalismo metafísico, ya sea sustantivo o metodológico, normativo o pluralista. [...] si acaso esta forma de hacer antropología se ocupa de asuntos de metafísica u "ontología" [...], lo hace para permitir que el objeto de análisis etnográfico ejerza un efecto transformativo sobre los supuestos ontológicos que el antropólogo trae consigo. [...] su preocupación central no es lo que es, sino lo que podría ser. (Holbraad y Pedersen, 2017, p. 68)

Es decir, se trata de "un proyecto metodológico que hace preguntas ontológicas para resolver problemas epistemológicos" (Holbraad y Pedersen, 2017, p. 5). Pero ¿en qué se distingue, entonces, del proyecto de EVC? A diferencia de este último, Holbraad no aceptaría sustituir en la cita anterior el adjetivo "epistemológico" por el adjetivo "político", porque defiende que la antropología tiene que limitarse a posibilitar que aquéllos a los que se dirige se pronuncien por sí mismos sobre cuestiones éticas y políticas (Holbraad y Viveiros de Castro, 2016, pp. 9-10).

Abro un paréntesis para intentar poner en la mira al principal adversario de EVC y los distintos giros ontológicos: aquella ontología moderna que aparentemente prohíbe hacer preguntas ontológicas y con la que el proyecto crítico kantiano parece haber establecido un vínculo privilegiado. No resulta tan fácil enfocar el lente en ésta. Respecto a la teoría amerindia del perspectivismo, uno de sus flancos vulnerables es precisamente la oposición entre el multinaturalismo amerindio y el mononaturalismo occidental, que EVC construye, según Terence Turner, "no tanto por medio de la descripción y el análisis etnográficamente fundamentado [...], sino por medio de un diálogo filosófico entre formulaciones típico-ideales de ideas occidentales modernistas y representaciones generales de ideas culturales supuestamente comunes entre los amazónicos" (Turner, 2009, pp. 15-16).

Un vistazo somero a una propuesta elaborada dentro de los parámetros de esta ontología moderna no sólo pone al descubierto el riesgo de observar un bosque mononaturalista donde realmente hay un conjunto de árboles bastante variados, algo de lo que EVC está plenamente consciente (véase, por ejemplo, Viveiros de Castro, 2015b, pp. 211-213), sino también el de asumir que el proyecto crítico kantiano desemboca inevitablemente 
en el mononaturalismo. Reivindicando explícitamente sus raíces kantianas, Olimpia Lombardi y Ana Rosa Pérez (2012) abogan en Los múltiples mundos de la ciencia: Un realismo pluralista y su aplicación a la filosofía de la física a favor de un pluralismo ontológico que mapea una multiplicidad de mundos conceptualmente constituidos, cada uno de los cuales es el resultado de la conjunción entre un esquema conceptual y la realidad independiente. A mi parecer, uno de sus aspectos más sorprendentes es su dimensión sincrónica: mientras los chamanes amazónicos de EVC son capaces de cruzar las barreras entre las distintas especies -animales, espíritus, objetos, plantas, etcétera- y adoptar sus respectivas perspectivas, los físicos de Lombardi y Pérez operan simultáneamente con teorías que presuponen ontologías inconmensurables - la teoría de la relatividad y la mecánica cuántica, por ejemplo- y parecen habitar varios mundos al mismo tiempo. Además, el realismo de Lombardi y Pérez no se circunscribe al ámbito restringido de la ciencia: entre estos múltiples mundos también hay mundos no científicos como los del sentido común, lo que abre la puerta para llevarlo más allá de los expertos, ya sean chamanes o científicos.

Empero, desde la perspectiva de los distintos giros ontológicos en la antropología y la filosofía contemporáneas, el defecto de ontologías como la de Lombardi y Pérez reside en haberse encerrado en lo que Francis Wolff describe como la "jaula transparente del lenguaje" (Wolff, 1997, p. 11). El examen de Después de la finitud: Ensayo sobre la necesidad de la contingencia del realista especulativo Quentin Meillassoux, considerado "uno de los libros más influyentes en el área" (Holbraad y Pedersen, 2017, p. 33), no sólo permite desmenuzar esta acusación, sino también ponderar la dimensión ontológica del movimiento en su totalidad. Simplificando, Meillassoux divide la historia de la filosofía moderna en tres. En primer lugar, el fundacionalismo de Descartes marca el advenimiento de las metafísicas dogmáticas, que se caracterizan por reivindicar un realismo directo ingenuo en donde la existencia de Dios garantiza la existencia de objetos absolutos, que son independientes del sujeto.

En segundo lugar, el giro copernicano de Kant instaura la idea del lenguaje como una jaula y de un mundo objetual que no es independiente del sujeto, generando "la sorda impresión de haber perdido irremediablemente el Gran Afuera, el Afuera absoluto de los pensadores precríticos [...] 
que no era relativo a nosotros, [...] al existir como es en [sí] mismo, lo pensemos o no" (Meillassoux, 2006/2015, p. 32). ¿Quiénes son, en este caso, los principales implicados? En A Thing of This World: A History of Continental Anti-Realism, Lee Braver rastrea la radicalización de la idea kantiana de que "la mente, más que reflejar pasivamente una realidad independiente, procesa y organiza activamente la experiencia al construir conocimiento" (Braver, 2007, p. 3) para reconstruir la historia del antirrealismo continental, en donde Hegel, Nietzsche, Heidegger, Foucault y Derrida ocupan los papeles protagónicos. Para poner más claramente en la mira a sus adversarios, Meillassoux propone sustituir el término de antirrealismo por el de "correlacionismo", con el que agrupa "toda corriente de pensamiento que sostenga [...] la idea según la cual no tenemos acceso más que a la correlación entre pensamiento y ser" (Meillassoux, 2006/2015, pp. 29-30). ${ }^{14}$

Y en tercer lugar, al igual que la constelación más amplia de giros ontológicos en general, el realismo especulativo constituye una rebelión abierta en contra del movimiento puesto en marcha por Kant y pretende cimentar un nuevo realismo directo para garantizar el acceso al Gran Afuera sin volver a los dogmatismos precríticos. Sin entrar en los detalles, la respuesta de Meillassoux a esta apuesta no correlacionista -y, por lo tanto, también no representacionalista- consiste en postular la existen-

14 Aun cuando el análisis exhaustivo del proyecto de Meillassoux excede los confines de este artículo, añado algunos apuntes adicionales a modo de preámbulo para el siguiente y último apartado, en donde rastreo los paralelismos insospechados entre los proyectos de EVC y el último Foucault. Al profundizar su crítica del correlacionismo, Meillassoux distingue dos tipos: mientras que los correlacionistas débiles, como el propio Kant, defienden que el Gran Afuera es incognoscible pero pensable, los correlacionistas fuertes, hoy en día dominantes, mantienen que no es cognoscible ni pensable. Según él, sobre todo la postura de estos últimos resulta problemática, porque, al sostener que no se puede excluir la posibilidad de que el principio de no contradicción no aplique afuera de la jaula del lenguaje, no sólo inhabilitan a la razón para salir de ésta, sino también abren la caja de Pandora para el retorno de lo religioso bajo la forma de incursiones irracionales irrestrictas en el Gran Afuera, a menudo en nombre de la alteridad radical, ya que "se convierte en racionalmente ilegítimo descalificar un discurso no racional sobre [lo] absoluto con el pretexto de su irracionalidad" (Meillassoux, 2006/2015, p. 72). Esto implica que, para Meillassoux, el pensamiento de un correlacionista fuerte como Foucault y el del gurú indio Bhagwan Shree Rajneesh, mejor conocido como Osho y autor de libros como Zorba the Buddha, son dos caras de la misma moneda. Como mostraré en adelante, nada es menos cierto, ya que el lugar adonde llegó Foucault a inicios de la década de 1980 y el que se vislumbra desde el proyecto de EVC no son tan diferentes.

Moszowski, A. (2021). Alteridad, lenguaje y ontología en la antropología perspectivista de Eduardo Viveiros de Castro: reflexiones extemporáneas. Iberoforum. Revista de Ciencias Sociales, Nueva Época, 1(2), 1-33, Artículos, e000161. https://doi.org/10.48102/if.2021.v1.n2.161 Licencia Pública Internacional - CC BY-NC-ND 4.0 
cia de un hiper-Caos afuera de la jaula y la potencia de las matemáticas para aprehenderlo.

Respecto al giro ontológico de Holbraad y Pedersen, en donde el "tomar en serio" de EVC ocupa un lugar privilegiado, sus integrantes mantienen una relación ciertamente ambivalente con el proyecto de Meillassoux, en donde la antropología no ocupa ningún lugar. Sin duda, suscribirían las palabras de Casper Bruun Jensen, quien, refiriéndose a la autodeterminación ontológica de los pueblos, enfatiza que éste "se opone directamente al giro ontológico en la antropología" (Jensen, 2013, p. 327). No obstante, al igual que en el caso de EVC, la posibilidad de erigir una barrera infranqueable entre esta antropología y las otras no sólo depende de la alteridad de aquellos cuyo pensamiento es "tomado en serio", sino también de la posibilidad de reivindicar implícitamente un nuevo realismo directo capaz de garantizar un acceso no mediado por el lenguaje a "lo que hay". En efecto, cabe preguntarse por qué este proyecto esencialmente metodológico se bautizó como un "giro ontológico" y no como un "giro metodológico". ${ }^{15}$ Según Paolo Heywood, "Holbraad y otros utilizan la palabra 'ontología' precisamente por las connotaciones de 'realidad' y 'ser' que acarrea [...] a pesar de sostener al mismo tiempo, y algo paradójicamente, que no están describiendo el o los mundos, sino aproximándose a éstos" (Heywood, 2012, pp. 146, 150n6). Sea cual sea la respuesta, al presentarlo como un "giro ontológico", se abre la puerta para generar la impresión de tener un alcance ontológico similar al de los otros giros ontológicos, que en su conjunto, y como mostré con base en el proyecto de Meillassoux, apuntan al desarrollo de un nuevo realismo directo, cuya ambición queda perfectamente expresada en las siguientes palabras: “¡Abajo Kant! ¡Abajo la Crítica! Volvamos al mundo, aún desconocido y despreciado" (Latour, 1988, p. 173). Sin embargo, al rechazar explícitamente cualquier pretensión metafísica, el terreno es preparado para llamarse andana si estos otros giros ontológicos no logran cumplir lo que prometen.

15 De nuevo, cabe destacar la particularidad del proyecto de Holbraad y Pedersen, quienes sostienen que la antropología tiene que limitarse a posibilitar que aquéllos a los que se dirige se pronuncien por sí mismos sobre cuestiones éticas y políticas. Muchos de los partidarios y simpatizantes de los diversos acercamientos ontológicos en la antropología contemporánea disentirían de lo anterior y defenderían, al igual que EVC, que no se trata de un giro meramente metodológico, sino sobre todo político (véase, por ejemplo, Charbonnier et al., 2016, pp. 8-9). Empero, desde esta perspectiva, cabe preguntarse por qué se bautizó como un "giro ontológico" y no como un "giro político".

Moszowski, A. (2021). Alteridad, lenguaje y ontología en la antropología perspectivista de Eduardo Viveiros de Castro: reflexiones extemporáneas. Iberoforum. Revista de Ciencias Sociales, Nueva Época, 1(2), 1-33, Artículos, e000161. https://doi.org/10.48102/if.2021.v1.n2.161 Licencia Pública Internacional - CC BY-NC-ND 4.0 
Otro ámbito en donde se refleja el compromiso implícito de EVC y los integrantes del giro ontológico de Holbraad y Pedersen con un realismo como el de Meillassoux es en su posicionamiento en el debate sobre la antropología posmoderna, que se halla firmemente ubicada en el círculo correlacionista. En lo que se refiere a ésta, la independencia política de las últimas colonias generó una crisis en la antropología que puso en tela de juicio las representaciones etnográficas y obligó a poner bajo la lupa la dimensión ético-política de las diferentes formas de construcción textual, un reto que fue asumido por los nueve colaboradores de Writing Culture: The Poetics and Politics of Ethnography (Clifford y Marcus, 1986), alrededor de los cuales se articuló en las décadas de 1980 y 1990 un movimiento heterogéneo que apostó por la crítica metaantropológica y la etnografía experimental para contribuir a desarrollar una antropología reflexiva capaz de responder al llamamiento de "dar voz al otro".

En cuanto a EVC, quien se acerca a la brecha entre el lenguaje y la realidad desde la teoría semiótica de Roy Wagner, aunque sus seguidores incluyen tanto la antropología posmoderna como la antropología fenomenológica, que incita a enfocarse en "las cosas como son", entre sus "precursores teóricos y metodológicos" (Holbraad y Pedersen, 2017, p. 285), la priorización perspectivista de las conceptualizaciones nativas sobre la narratividad local y el descuido consciente y voluntario de la escritura en sus propios textos etnográficos demuestran el distanciamiento con respecto a ésta. Como aclara EVC en el prefacio de su etnografía From the Enemy's Point of View: Humanity and Divinity in an Amazonian Society, "nunca aspiré a experimentar con géneros literarios [...] Aun cuando quedará expuesto que la polifonía y el dialogismo son características notables de la cultura araweté, no impregnan el tejido de mi descripción. Esto no me ha quitado el sueño" (Viveiros de Castro, 1986/1992, p. xvii).

Ahora bien, la viabilidad antropológica de esta decisión de descuidar la escritura depende en gran parte del supuesto de haber salido exitosamente de la jaula del lenguaje, algo que no es nada evidente, como no sólo sugiere la naturaleza intrínsecamente imprecisa del lenguaje etnográfico, que, aun en el caso de EVC, se nutre de acopios conceptuales muy variados, sino también el carácter intuitivamente insatisfactorio de la salida propuesta por Meillassoux, quien reivindica el lenguaje mucho más analítico de las matemáticas. A mi juicio, teniendo presente el carácter fuertemente 
disputado de este supuesto, convendría ser más prudente y no descuidar la escritura etnográfica, como sugirieron los antropólogos posmodernos, ya que, en el caso de no haberse salido realmente de la jaula, esto podría ser contraproducente: desde esta perspectiva, por ejemplo, aun cuando en un texto etnográfico no hay una correspondencia de uno a uno entre las estrategias retóricas, los supuestos filosóficos y las implicaciones ético-políticas, es riesgoso explorar por separado las aristas de este triángulo, porque existe el peligro de disociar la forma escritural del contenido crítico, minando así a este último.

El caso de Taussig, cuya trayectoria heterodoxa se desplegó en la periferia exterior de la antropología posmoderna, es ilustrativo. Cuando Pedersen, uno de los coautores de The Ontological Turn: An Anthropological Exposition, argumenta en su etnografía Not Quite Shamans: Spirit Worlds and Political Lives in Northern Mongolia que "el humor chamánico, en lugar de conducir a la 'opacidad epistemológica' de Taussig, constituye una oportunidad única para ejemplificar en el lenguaje que es el cosmos el que es relativo y no las representaciones que se hacen de éste" (Pedersen, 2011, p. 213), pasa por alto que los montajes literarios de Taussig, que intentan replicar el desorden ordenado de las sesiones ayahuasqueras de los chamanes indígenas del Putumayo, Colombia, tienen implicaciones ontológicas. ${ }^{16}$ Es más, también el libro de su propia mano, escrito en un lenguaje mucho más ortodoxo, tiene implicaciones ontológicas, que potencialmente contravienen la ontología chamánica y la narratividad correspondiente en las que se enfoca.

\section{Reflexiones finales: ¿más allá del lenguaje?}

EVC defiende su proyecto antropológico, que incita a "tomar en serio" el pensamiento nativo, como "la ciencia de la autodeterminación ontológica de los pueblos del mundo" (Viveiros de Castro, 2003/2015a, p. 54), cuya mi-

16 Desde esta perspectiva, Shamanism, Colonialism, and the Wild Man: A Study in Terror and Healing (Taussig, 1987), una etnografía escrita en forma de montaje literario que se enfoca en las secuelas del terror cauchero y la "opacidad epistemológica y ontológica" correspondiente, marca muy claramente un antes y un después. A diferencia de sus textos anteriores, cuya estructura demasiado ordenada socava la apuesta política subyacente, porque reproduce la "metafísica del orden" que sigue causando tantos estragos en el mundo, el libro articula de manera coherente una serie de estrategias retóricas, supuestos filosóficos e implicaciones ético-políticas que reaparecen en todos sus escritos posteriores, entre los que se destaca The Magic of the State (Taussig, 1997).

Moszowski, A. (2021). Alteridad, lenguaje y ontología en la antropología perspectivista de Eduardo Viveiros de Castro: reflexiones extemporáneas. Iberoforum. Revista de Ciencias Sociales, Nueva Época, 1(2), 1-33, Artículos, e000161. https://doi.org/10.48102/if.2021.v1.n2.161 Licencia Pública Internacional - CC BY-NC-ND 4.0 
sión consiste en convertirse en "la teoría-práctica de la descolonización permanente del pensamiento" (Viveiros de Castro, 2009/2010a, p. 14). Respecto a su dimensión metodológica, las viñetas reunidas en el apartado "La seriedad como metodología y el problema de la alteridad" pusieron en tela de juicio la idea de alteridad en la que se sustenta y que, según algunos de sus críticos, contribuye a instaurar una especie de "apartheid ontológico" (Laidlaw, 2012, s.p.). A su vez, las reflexiones intermedias se enfocaron en el posfundacionalismo de Paul Feyerabend, que parte del supuesto de que "todo sirve para algo mas no para todo", para tratar de llevar la seriedad perspectivista más allá de la alteridad y recalibrar la relación entre los llamados "nativos" y los antropólogos. De esta forma, el peso de la justificación etnográfica se trasladaría de la alteridad de los primeros a las decisiones metodológicas concretas de los últimos de "tomar en serio" esta idea, y no otra, de esta persona, y no otra. Mas no sólo eso. La antropología de EVC perdería su condición excepcionalista, porque ya no podría distanciarse radicalmente de las antropologías anteriores. Lejos de resultar perjudicial, esto nutriría el pluralismo epistemológico tan necesario para la ciencia, lo cual no sólo fortalecería el proyecto del propio EVC, ya que la mejor forma de robustecer una teoría es intentar atacarla por medio de la exploración de la mayor cantidad posible de alternativas, sino también la antropología en general, que requiere del diálogo inter y extraparadigmático para seguirse reconstruyendo en alta mar como los navíos de Otto Neurath a los que aludí en la introducción de este escrito.

Respecto a la dimensión ontológica del proyecto de EVC, las viñetas reunidas en el apartado "La ontología como mundo y el problema del lenguaje" rastrearon las semejanzas y las diferencias entre éste y la constelación mucho más amplia de giros ontológicos en la antropología y la filosofía contemporáneas. Mostré que detrás de su aspiración de desmarcarse de la antropología heredada se trasluce el mismo deseo de "volver al mundo", lo cual se refleja tanto en su hostilidad hacia las representaciones o las "visiones del mundo" como en su intento de desplegar implícitamente una teoría no representacionalista del lenguaje para aprehender directamente los "mundos de la visión". En cuanto a este desafío tan ambicioso, la intrincada respuesta de Meillassoux, el influyente exponente de uno de estos giros ontológicos reveló que esto no es nada evidente. Sea como fuere, en estas reflexiones finales esbozo una tercera respuesta posible, que permite arrojar una luz distinta sobre el proyecto de EVC. 
Para ello, dirijo la mirada a Michel Foucault, cuyo nombre no aparece ni una sola vez en Después de la finitud: Ensayo sobre la necesidad de la contingencia de Meillassoux, pero que es uno de sus principales adversarios. Sin lugar a duda, el proyecto filosófico que inició con la historización del objeto en sus periodos arqueológico y genealógico y culminó con la del sujeto y la verdad del llamado "último Foucault", merece un lugar entre los correlacionismos más radicales. Como apunta Marshall Berman, se trata de "una serie interminable y atormentada de variaciones sobre los temas weberianos de la jaula de hierro [...] en el mundo de Foucault no hay libertad porque su lenguaje forma [...] una jaula mucho más hermética" (Berman, 1982/1988, pp. 24-25). Empero, las seis conferencias que impartió en 1983 en la Universidad de Berkeley, transcritas en Discourse and Truth and Parrēsia, ofrecen una ventana insospechada más allá de la jaula del lenguaje y abren la puerta para repensar su proyecto original, aunque sorprendentemente sin la necesidad de modificar sus parámetros esenciales. En ellas, Foucault se enfoca en la problematización de la parrēsia entre los siglos $\mathrm{V}$ a. C. y II d. C., una noción griega que en su sentido positivo pone de relieve una relación privilegiada con la verdad:

Parrēsiazein o parrēsiazesthai significa "decir la verdad". Pero esto no queda del todo claro. ¿Dice el parrēsiastēs lo que él cree que es verdadero o dice lo que es realmente verdadero? Y la respuesta es que el parrēsiastēs dice lo que es verdadero porque él cree que es verdadero. Y él piensa que es verdadero porque es realmente verdadero. (Foucault, 2016/2019, pp. 41-42)

Además, resalta al menos dos elementos. Para empezar, esboza el desplazamiento del lugar de revelación de la verdad de Delfos, donde los dioses desvelan la verdad a través de la Pitia, a Atenas, donde los humanos enuncian la verdad por medio de la parrēsia, en la que, en sus propias palabras, "el hablante utiliza su libertad y elige la verdad en lugar de la mentira, la muerte en lugar de la vida y la seguridad, la crítica en lugar de la adulación, y el deber en lugar del egoísmo" (Foucault, 2016/2019, p. 46). Es decir, en el contexto cartesiano la coincidencia entre una creencia y la verdad depende de una experiencia mental probatoria a partir de la cual uno adquiere la verdad, mientras que en el de la parrēsia depende de la actividad verbal de alguien con determinadas cualidades morales: la franqueza, el coraje ante 
el peligro de muerte y el deber de la crítica asimétrica desde abajo. Por otra parte, reconstruye el tránsito de una parrēsia política, en donde el énfasis recae en el decir, a una parrēsia personal o filosófica, en donde el énfasis recae en el hacer. Respecto a esta última, no sólo recalca la figura de Sócrates, que exhibe una armonía ontológica entre logos o lo que dice y bios o lo que hace, sino también la de Diógenes "El Perro", que, al igual que los otros filósofos cínicos, sostenía que la vida que uno vive es la piedra de toque de su relación con la verdad y, en concordancia con ello, ordenó desde su tinaja al aire libre que Alejandro Magno se alejara para seguir tomando el sol.

¿Qué se sigue de esto para lo expuesto en este escrito? Aun teniendo en mente la advertencia de que "la parrēsia no puede realizarse al interior de nuestro marco epistemológico desde Descartes en adelante" (Foucault, 2016/2019, p. 52), sería revelador ponderar quién está en una posición más favorable para atravesar las barras de la jaula del lenguaje: el matemático de Meillassoux; el antropólogo perspectivista, que hace recaer el peso en la alteridad de aquellos cuyo pensamiento es "tomado en serio"; o el parrēsiastēs, que por sus cualidades morales singulares puede hacer coincidir performativamente lo que piensa, lo que dice, lo que hace y "lo que hay". Aun cuando la examinación exhaustiva del problema de la verdad que se encuentra en el fondo de la pregunta anterior excede por mucho los confines de este artículo, esbozo una respuesta posible.

Simplificando, las reflexiones sobre la parrēsia ponen en tela de juicio el lugar de emergencia de la verdad, que se traslada de aquel que escribe a aquel sobre el que se escribe. No obstante, de ahí no se sigue que la condición existencial de este último sea una razón suficiente para justificar lo que se escribe sobre él. A mi juicio, a menos que aquel que escribe también resulta ser un parrēsiastēs, cabe poner el problema de la verdad provisionalmente entre paréntesis y revalorar la importancia de aquello que está al alcance de todos, seamos practicantes de la parrēsia o no: la justificación, en donde el peso recae en la disposición de dar razones intersubjetivamente suficientes. Obviamente, todo ello sin olvidar que "todas las metodologías, incluso las más obvias [como la justificación], tienen sus límites" (Feyerabend, 1975/1986, p. 17). Por más paradójico que sea, del hecho de que tanto justificar como no justificar sirve para algo, mas no para todo, no se sigue que se trate de una herramienta prescindible en la arena posfundacionalista, en donde la búsqueda posible y necesaria de fundamentos provisionales sustituye la búsqueda infructuosa de fundamentos últimos. 
Desde esta perspectiva, resulta sugerente voltear la mirada a The Falling Sky: Words of a Yanomami Shaman, la etnografía colaborativa del chamán yanomami Davi Kopenawa y el etnólogo francés Bruce Albert. Como apunta este último, se trata de una colección de viñetas autobiográficas y reflexiones chamánicas de Kopenawa, quien "no sólo esperaba denunciar las amenazas directas que acechan a los yanomami y la selva amazónica, sino también hacer un llamado, en su papel de chamán, en contra del extenso daño causado por "la gente de la mercancía" (Kopenawa y Albert, 2010/2013, p. 8). Es decir, no se trata de un texto etnográfico en donde un antropólogo "toma en serio" el pensamiento de los nativos, sino de un escrito en donde uno de ellos habla. ¿Cuál es la diferencia? Mientras que una etnografía como From the Enemy's Point of View: Humanity and Divinity in an Amazonian Society de EVC se encuentra necesariamente sujeta a cuestionamientos disciplinarios - por ejemplo, sobre su dimensión metodológica y el problema de la alteridad o su dimensión ontológica y el problema del lenguaje-, en el caso de una obra como The Falling Sky: Words of a Yanomami Shaman todo ello se vuelve irrelevante. ¿Por qué? Pierden sentido las preguntas por la alteridad de aquellos cuyo pensamiento es "tomado en serio" y la relación entre lo que el antropólogo escribe y las cosas, pero adquiere centralidad la cuestión de qué tan diferentes son las prácticas de Kopenawa y el parrēsiastēs. Evidentemente, para evitar cualquier confusión, hay que distinguir entre la práctica de Kopenawa y el texto coescrito con Albert, ya que, de lo contrario, podría generarse la impresión de que se trata de una figura ilusoria que emana de una creación literaria. En el caso de la parrēsia, la única piedra de toque es la práctica del parrēsiastēs, que no requiere de un voceador, a menos que éste así lo desea, por lo que, si las prácticas de Kopenawa y el parrēsiastēs resultan parecidas, el estatuto de este texto escrito a cuatro manos depende de lo que diga Kopenawa y no de lo que digamos nosotros. ${ }^{17}$

17 Tal vez la forma más apropiada de acercarse a la parrēsia es concibiéndola como una aporía y no como un ideal. ¿Qué hacer cuando el parrēsiastēs niega serlo? Desde esta perspectiva, el interés de Foucault por la parrēsia es perfectamente congruente con su lugar prominente entre aquellos que Cesáreo Morales (2007) describe como los pensadores del "acontecimiento" y su carácter aporético, entre los que también se destacan Gilles Deleuze y Jacques Derrida. 
A modo de cierre, pero reconociendo la necesidad de seguir debatiendo, reproduzco las palabras con las que el chamán yanomami inicia el libro, que sorprendentemente aún no ha sido traducido al español:

La selva está viva. Sólo puede morir si los blancos persisten en destruirla. Si lo logran, los ríos desaparecerán bajo tierra, la tierra se desmoronará, los árboles se secarán y las piedras se resquebrajarán bajo el calor. La tierra seca se volverá vacía y silenciosa. Los espíritus xapiri que bajan de las montañas para jugar sobre sus espejos en la selva huirán lejos. Sus padres chamanes ya no podrán sumarlos y hacerlos bailar para protegernos. Ya no tendrán poder para repeler los vapores epidémicos que nos devoran. Ya no podrán contener los seres malignos que convertirán la selva en un caos. Moriremos uno tras otro, tanto los blancos como nosotros. Finalmente todos los chamanes desaparecerán. Entonces, cuando ya no haya nadie para sostenerlo, se caerá el cielo. (Kopenawa y Albert, 2010/2013, p. xvii)

Lo anterior demuestra que el lugar adonde llegó el último Foucault y el que se vislumbra en el horizonte desde la antropología perspectivista de EVC no son tan distintos: tal vez la respuesta a la pregunta por el "más allá" del lenguaje no se encuentra en lo que escribe aquél que "toma en serio" el pensamiento nativo, sino en la práctica de aquél que es como el parrēsiastēs. De hecho, esto no sólo pone al descubierto la relevancia del diálogo inter y transdisciplinario para tender puentes entre proyectos aparentemente antagónicos, sino también para clarificar y reafirmar la apuesta política subyacente al proyecto de EVC, que trasciende por mucho los confines estrechos de cualquier disciplina en particular.

\section{Referencias bibliográficas}

Berman, M. (1988). Todo lo sólido se desvanece en el aire: La experiencia de la modernidad. Siglo XXI. (Trabajo original publicado en 1982).

Braver, L. (2007). A Thing of This World: A History of Continental Anti-Realism. Northwestern University Press.

Candea, M. (2011). Endo/Exo. Common Knowledge, 17(1), 146-150. https:// doi.org/10.1215/0961754X-2010-046

Charbonnier, P., Salmon, G. y Skafish, P. (2016). Introduction. En P. Charbon- 
nier, G. Salmon y P. Skafish (eds.), Comparative Metaphysics: Ontology after Anthropology (pp. 1-23). Rowman \& Littlefield International.

Clifford, J. y Marcus, G. E. (eds.) (1986). Writing Culture: The Poetics and Politics of Ethnography. University of California Press.

Course, M. (2010). Of words and fog: Linguistic relativity and Amerindian ontology. Anthropological Theory, 10(3), 247-263. https://doi. org/10.1177/1463499610372177

dos Santos, A. y Tola, F. (2016). ¿Ontologías como modelo, método o política? Debates contemporáneos en antropología. Avá, (29), 71-98. http:// www.ava.unam.edu.ar/images/29/n29a03.pdf

Feyerabend, P. (1986). Tratado contra el método: Esquema de una teoría anarquista del conocimiento. Tecnos. (Trabajo original publicado en 1975).

Foucault, M. (2019). Discourse and Truth and Parrēsia. University of Chicago Press. (Trabajo original publicado en 2016).

González-Abrisketa, O. y Carro-Ripalda, S. (2016). La apertura ontológica de la antropología contemporánea. Revista de Dialectología y Tradiciones Populares, 71(1), 101-128. https://doi.org/10.3989/rdtp.2016.01.003

González, S. A. (2015). Antropología y el estudio de las ontologías a principios del siglo XXI: Sus problemáticas y desafíos para el análisis de la cultura. Estudios sobre las Culturas Contemporáneas, 21(42), 39-64. http://revistasacademicas.ucol.mx/index.php/culturascontemporaneas/article/view/1803

Henare, A., Holbraad, M. y Wastell, S. (2007). Introduction: Thinking through things. En A. Henare, M. Holbraad y S. Wastell (eds.), Thinking Through Things: Theorising Artefacts Ethnographically (pp. 1-31). Routledge.

Heywood, P. (2012). Anthropology and what there is: Reflections on "ontology". Cambridge Anthropology, 30(1), 143-151. https://doi.org/10.3167/ ca.2012.300112

Holbraad, M. (2014). Tres provocaciones ontológicas. Ankulegi, (18), 127-139. https://aldizkaria.ankulegi.org/index.php/ankulegi/article/ view/69/179

Holbraad, M. y Pedersen, M. A. (2017). The Ontological Turn: An Anthropological Exposition. Cambridge University Press.

Holbraad, M. y Viveiros de Castro, E. (2016). Ideas of savage reason: Glass Bead in conversation with Martin Holbraad and Eduardo Viveiros de Castro. Glass Bead Journal, (0), 1-12. https://www.glass-bead.org/ article/ideas-of-savage-reason-glass-bead-in-conversation-with- 
martin-holbraad-and-eduardo-viveiros-de-castro/?lang=enview

Jensen, C. B. (2013). Two forms of the outside: Castaneda, Blanchot, ontology. HAU, 3(3), 309-335. https://doi.org/10.14318/hau3.3.013

Kopenawa, D. y Albert, B. (2013). The Falling Sky: Words of a Yanomami Shaman. Belknap Press of Harvard University Press. (Trabajo original publicado en 2010).

Laidlaw, J. (2012). Ontologically challenged. Anthropology of this Century, (4), s. p. http://aotcpress.com/articles/ontologically-challenged

Latour, B. (1988). The politics of explanation: An alternative. En S. Woolgar (ed.), Knowledge and Reflexivity: New Frontiers in the Sociology of Knowledge (pp. 155-176). Sage.

Lombardi, O. y Pérez, A. R. (2012). Los múltiples mundos de la ciencia: Un realismo pluralista y su aplicación a la filosofía de la física. Universidad Nacional Autónoma de México, Siglo XXI.

López, P. y Acevedo-Rodrigo, A. (eds.) (2018). Beyond Alterity: Destabilizing the Indigenous Other in Mexico. University of Arizona Press.

Meillassoux, Q. (2015). Después de la finitud: Ensayo sobre la necesidad de la contingencia. Caja Negra. (Trabajo original publicado en 2006).

Morales, C. (2007). Fractales: Pensadores del acontecimiento. Siglo XXI.

Neurath, J. (2020). La contemporaneidad del ritual indígena. Iberoforum, 15(29), 1-22. https://iberoforum.ibero.mx/index.php/iberoforum/ article/view/37/30

Neurath, O. (1944). Foundations of the Social Sciences. University of Chicago Press.

Pedersen, M. A. (2011). Not Quite Shamans: Spirit Worlds and Political Lives in Northern Mongolia. Cornell University Press.

Reygadas, L. (2019). Crítica del dualismo crítico: El retorno de los enfoques esencialistas en el análisis de la cultura. Sociológica, 34(96), 73-106. http://www.sociologicamexico.azc.uam.mx/index.php/Sociologica/article/view/1498

Suárez, R. (2008). Breve introducción al pensamiento de Feyerabend. Universidad Autónoma Metropolitana.

Taussig, M. (1987). Shamanism, Colonialism, and the Wild Man: A Study in Terror and Healing. University of Chicago Press.

Taussig, M. (1993). Mimesis and Alterity: A Particular History of the Senses. Routledge.

Taussig, M. (1997). The Magic of the State. Routledge. 
Tobón, M. (2016). Reírse ante la guerra: Las bromas como actuación política entre los muina, Amazonia colombiana. Revista Mexicana de Sociología, 78(2), 179-202.

Turner, T. (2009). The crisis of late structuralism. Perspectivism and animism: Rethinking culture, nature, spirit, and bodiliness. Tipití, 7(1), 3-40. https://digitalcommons.trinity.edu/tipiti/vol7/iss1/1

Venkatesan, S., Carrithers, M., Candea, M., Sykes, K. y Holbraad, M. (2010). Ontology is just another word for culture: Motion tabled at the 2008 meeting of the group for debates in anthropological theory, University of Manchester. Critique of Anthropology, 30(2), 152-200. https://doi.org/10.1177/0308275X09364070

Viveiros de Castro, E. (1992). From the Enemy's Point of View: Humanity and Divinity in an Amazonian Society. University of Chicago Press. (Trabajo original publicado en 1986).

Viveiros de Castro, E. (2004). Perspectival anthropology and the method of controlled equivocation. Tipití, 2(1), 3-22. https://digitalcommons. trinity.edu/tipiti/vol2/iss1/1

Viveiros de Castro, E. (2010a). Metafísicas caníbales: Líneas de antropología postestructural. Katz. (Trabajo original publicado en 2009).

Viveiros de Castro, E. (2010b). The untimely, again. En P. Clastres, Archaeology of Violence (pp. 9-51). Semiotext(e).

Viveiros de Castro, E. (2011). Zeno and the art of anthropology: Of lies, beliefs, paradoxes, and other truths. Common Knowledge, 17(1), 128-145. https://doi.org/10.1215/0961754X-2010-045

Viveiros de Castro, E. (2014). Llevar a serio... contra el infierno metafísico de la antropología: Entrevista con Eduardo Viveiros de Castro. Anales de Antropología, 48(2), 219-244. http://dx.doi.org/10.1016/S01851225(14)70252-8

Viveiros de Castro, E. (2015a). And. En The Relative Native: Essays on Indigenous Conceptual Worlds (pp. 39-54). HAU Books. (Trabajo original publicado en 2003).

Viveiros de Castro, E. (2015b). Cosmological perspectivism in Amazonia and elsewhere (Four lectures given in the Department of Social Anthropology, University of Cambridge, February-March 1998). En The Relative Native: Essays on Indigenous Conceptual Worlds (pp. 189-294). HAU Books.

Viveiros de Castro, E. (2016). Metaphysics as mythophysics: Or, why I have

Moszowski, A. (2021). Alteridad, lenguaje y ontología en la antropología perspectivista de Eduardo Viveiros de Castro: reflexiones extemporáneas. Iberoforum. Revista de Ciencias Sociales, Nueva Época, 1(2), 1-33, Artículos, e000161. https://doi.org/10.48102/if.2021.v1.n2.161 Licencia Pública Internacional - CC BY-NC-ND 4.0 
always been an anthropologist. En P. Charbonnier, G. Salmon y P. Skafish (eds.), Comparative Metaphysics: Ontology After Anthropology (pp. 249-274). Rowman \& Littlefield International.

Wolfendale, P. (2014). Object-Oriented Philosophy: The Noumenon's New Clothes. Falmouth.

Wolff, F. (1997). Dire le monde. Presses universitaires de France.

Yébenes, Z. (2014). Los espíritus y sus mundos: Locura y subjetividad en el México moderno y contemporáneo. Universidad Autónoma Metropolitana, Gedisa. 